\title{
A tradução como estratégia de ensino e aprendizado contínuo
}

Maria Franca Zuccarello

Resumo: Com esta nossa comunicação objetivamos falar a respeito do trabalho que desenvolvemos como tradutores, de orientadores do estágio do Escritório Modelo de Tradução-Italiano, e da disciplina eletiva de Introdução aos Estudos de Tradução-Italiano I e II no curso de Graduação Português/Italiano, assim como professores da disciplina de Tradução (Italiano-Português e Português-Italiano) no curso de Especialização Latu Sensu. Porque, como professores de uma língua estrangeira, estamos sempre buscando novas e velhas formas de ensinar nossa língua. A tradução, apesar de ser considerada, já há muito tempo, uma metodologia superada, é uma excelente forma de ensinar e de aprender, pois traduzir textos permite que o tradutor esteja sempre em dia com o que há de mais recente nos campos literário e não literário. E, enfim, porque traduzir é uma arte e ser tradutor é ser um artista: é como se um pintor estivesse diante de uma tela e pintasse com outras cores um novo original, para que a mesma cena possa ser vista com outros olhos. A este propósito, queremos mostrar um trabalho desenvolvido no decorrer de nossas aulas de "Introdução aos Estudos de Tradução-Italiano": Ritratti d'autore, um pequeno livro composto por umas quarenta pequenas histórias, escrito por Mimmo Chisari, professor de Italiano e de Latim de uma pequena cidade siciliana. São histórias de personagens de uma das muitas cidadezinhas da Sićlia, que ele diz serem "personagens longinquas, quase indistinguiveis, fantasmas e sombras do passado, destinados com o tempo a desaparecer totalmente se não fossem, subitamente, fixados no papel para começar a existir de forma autônoma". Para nós, o autor faz uma pintura de cada história, onde os personagens são distantes da realidade atual da própria Sicilia, mas falam de heranças culturais que se renovam a cada nova escritura, a cada nova leitura, 
ampliando os nossos horizontes - e os de nossos alunos - para espaços mais vastos. Este foi um trabalho bastante gratificante, apesar de difícil porque, sendo o sujeito do livrinho a vida daquela cidade (assim como de muitas outras), os personagens usam o dialeto siciliano para se expressarem, e os dialetos são hoje "línguas" muito distantes da italiana, apesar de serem ainda muito usados por representarem a alma do povo.

Palavras-chave: Tradução. Tradutor. Ensino de tradução.

Abstract: In questa nostra comunicazione intendiamo parlare sul lavoro que sviluppiamo come traduttori, come tutor di tirocinanti dello Studio Modello di Traduzione - Italiano e delle discipline elettive Introduzione agli Studi di Traduzione - Italiano I e II, inserite nel corso di laurea Portoghese/Italiano, così come professori della disciplina Traduzione (Italiano-Portoghese e Portoghese-Italiano), nel corso dei Specializzazione Lato Sensu. Perché, come professori di una lingua straniera, stiamo sempre cercando nuove/vecchie forme per insegnare la nostra lingua. Tradurre, nonostante sia considerata, già da molto tempo, una metodologia superata, è un'eccellente forma di insegnare e di apprendere, visto che tradurre testi permette al traduttore di essere sempre aggiornato con ciò di più recente nel campo letterario e non letterario. $\mathrm{E}$ in ultima analisi perché tradurre è un'arte ed essere traduttore è lo stesso di essere un artista: è come se un pittore fosse davanti a un quadro e dipingesse con altri colori un nuovo originale, perché la stessa scena potesse essere vista con altri occhi. A questo proposito vogliamo mostrare un lavoro sviluppato durante le nostre lezioni di "Introduzione agli Studi di Traduzione - Italiano": Ritratti d'autore, un piccolo libro composto da una quarantina di storielle, scritto da Mimmo Chisari, professore di Italiano e di Latino in una piccola città siciliana. Sono storie di personaggi di una delle molte cittadine siciliane, che lui dice di essere "personaggi lontani, quasi indistinguibili, fantasmi e ombre del passato, destinati con il tempo a scomparire totalmente se non fossero, improvvisamente, fissati al ruolo per cominciare a esistere in modo 
autonomo". Per noi l'autore fa una pittura di ogni storia, una pittura in cui i personaggi sono distanti dalla realtà attuale della propria Sicilia, ma parlano di retaggio culturale che si rinnova in ogni nuova scrittura, in ogni nuova lettura, ampliando i nostri orizzonti - e quelli dei nostri alunni - per spazi più vasti. È stato un lavoro molto gratificante, malgrado difficile, perché essendo il soggetto del libriccino la vita di quella città (così come di molte altre), i personaggi usano il dialetto siciliano per esprimersi, e i dialetti sono oggi "lingue" molto distanti dall'italiano, malgrado siano ancora molto usati perché rappresentano l'anima del popolo.

Key words: Traduzione. Traduttore. Insegnamento della traduzione.

Ao propor esta comunicação o nosso principal objetivo não era dizer coisas novas, seja no que se refere às aulas de tradução, seja para a confecção deste trabalho, mas era o de fornecer instrumentos, principalmente aos nossos alunos, para uma reflexão sobre o ato de traduzir e da interdependência que existe entre os tipos de textos, entre a sua função linguística ou comunicativa e entre a forma de tradução. Ao mesmo tempo, queríamos oferecer-lhes estratégias tradutivas, práticas que enriquecem sua bagagem cultural, quando isto é entendido como meio de interculturalidade entre duas línguas, duas culturas, dois povos, dois Países.

A tradutologia das últimas décadas contribuiu para definir uma nova forma do ato de traduzir, porque agora a questão não se põe mais sobre como se deve traduzir, mas sobre uma reflexão a respeito do que acontece quando se traduz. A tradução agora não é mais entendida como a reprodução de singulares unidades de palavras ou frases, mas como um processo intercultural de transformação durante o qual uma língua (ou melhor, um texto) é traduzida para outra, ou seja, de um sistema cultural para outro. A traduzibilidade de textos, a princípio e entre alguns limites, é importante para entender o que acontece durante o processo de tradução, e como este pode produzir frutos para a didática. 
Então o objetivo desta nossa comunicação é falar brevemente a respeito da nossa experiência como Professora da disciplina "Introdução ao Estudo de tradução-italiano" e como Coordenadora dos estagiários do Escritório Modelo de Tradução-Italiano.

O processo tradutório é uma excelente forma de ensinar línguas e suas culturas, uma vez que permite ao tradutor e/ou ao professor de tradutologia estar sempre atualizado sobre o que há de mais recente - e também de mais antigo - seja no campo cultural, literário ou linguístico, seja em outro, e cada palavra traduzida corretamente representa um obstáculo vencido com sucesso. A propósito do ensino/aprendizagem da tradução - veículo de inserção da cultura de dois países cujas línguas estão sendo traduzidas -, o escritor e professor de tradução italiano, Bruno Osimo, diz que':

Ensinar tradução significa ensinar a (re) produzir textos funcionalmente equivalentes na língua de chegada. Se, portanto, a formulação de uma frase em língua de partida for standard, seja pelo léxico seja pela construção sintática, a mesma coisa deve ser na língua de chegada. Também neste caso resulta indispensável a contribuição do docente de análise textual, da narratologia e das disciplinas afins. (OSIMO, 1998, p. 20)

Entendemos que ensinar a traduzir, bem como fazer nossos alunos mergulharem na cultura do país representado pela linguagem, seja para nós professores uma aprendizagem contínua, porque as suas dificuldades nos motivam a buscar soluções para dissipá-las, e o que eles fazem corretamente nos serve de estímulo para que o nosso trabalho se torne cada vez mais satisfatório, tanto para nós como para eles.

Em um primeiro momento, passamos para os nossos alunos que, para nós, traduzir é uma arte e ser um tradutor significa ser um artista: é como se pegássemos um quadro já pintado por outra pessoa e o pintássemos, com o

\footnotetext{
${ }^{1}$ Insegnare traduzione significa insegnare a (ri)produrre testi funzionalmente equivalenti in LA (Língua di Arrivo). Se pertanto la formulazione di una frase in LP (Língua di Partenza) è standard, sia per il lessico sia per la costruzione sintattica, altrettant o deve essere in LA. Anche in questo caso risulta indispensabile il contributo dell'insegnante dell'analisi testuale, della narratologia e delle discipline affini. (OSIMO, 1998: 20)
} 
nosso próprio estilo e com outras cores, um novo original, a fim de que a mesma cena possa ser vista com outros olhos. Mais uma vez isso demonstra que traduzir não é apenas transportar um texto de uma língua para outra, mas é transformá-lo em um novo texto cuja leitura seja compreensível e aprazível para seu novo leitor, um leitor que lê o mesmo texto em outra língua. Isto nos deixou lembrar a capa de Ritratti d'autore, onde há um pintor que está pintando um quadro e dentro deste há várias cenas protagonizadas por vários personagens.

A realidade cultural da língua de partida tem uma grande influência porque, quando se transporta o texto traduzido para a língua de chegada, a tradução contribui para renovar e ampliar esta última, trazendo-lhe não somente um novo léxico, mas também inovações morfológicas, prosódicas e até mesmo sintáticas. Ideal seria que tais contribuições fossem oportunas e criativas, e não redundantes por conta da necessidade que o tradutor tem de fazer seu trabalho em tempo bastante restrito.

Um exemplo disso é o já citado Ritratti d'autore - Personaggi e tradizioni del passato, um livrinho de contos que usamos para as aulas práticas da disciplina mencionada.

O livro é composto por pouco mais de quarenta pequenas histórias sobre pessoas que viveram numa cidadezinha da Sicília do início dos anos 50 que foram eternizadas como personagens pela caneta de um professor da rede pública de ensino, que ali nasceu e cresceu. Esses personagens retratam, então, o pequeno mundo da infância do escritor ou fatos que lhe haviam sido contados.

Anche oggi le occasioni dello scrivere sono tante: alcune certamente le prime, sono da ricollegarsi ai ricordi della nostra vita, al mondo dell'infanzia pieno di personaggi lontani, quasi indistinguibili, fantasmi e ombre del passato, destinati, col tempo, a scomparire del tutto se non fossero, subito, fissati sulla carta per incominciare ad esistere in modo autonomo. ${ }^{3}$

\footnotetext{
${ }^{3}$ CHISARI, Mimmo. Ritratti d'autore - Personaggi e tradizioni del passato. Personal Editor, 1996.
} 
Mimmo Chisari, já há alguns anos, produz material para suas aulas e/ou para ser lido - e, muitas vezes, usado em outras aulas - até por nós no longínquo Brasil.

Como dissemos, o livro foi escrito por um siciliano, cujo código linguístico habitual é, claro, o dialeto siciliano. Todavia, enquanto professor e/ou escritor, seu código é a língua italiana. Nesse sentido, percebe-se que, ao escrever este livro, ele usou os dois códigos, uma vez que, ao reportar as falas de suas personagens, teve que usar o dialeto siciliano.

Isso, para quem sabe que na pequena Itália há mais de uma centena de dialetos, não seria um fato novo ou incompreensível, mas para os brasileiros cujas diferenças linguísticas regionais não são tantas quantas as da língua italiana - é inconcebível que haja tantos dialetos e que dois habitantes do mesmo país não se entendam só porque pertencem a regiões diferentes.

Naquela época, a unidade linguística italiana - ainda mais em pequenas cidades sicilianas, abandonadas pelo governo - estava longe de ter sido alcançada, até porque as personagens dos contos são homens e mulheres simples, pequenos artesãos ou ambulantes, os quais sabiam que ao lado do dialeto siciliano havia a língua italiana, língua essa que não sabiam falar porque naquele tempo era falada e/ou escrita somente por poucas pessoas cultas e, mesmo assim, em ambientes de cultura.

O trabalho em sala de aula foi muito proveitoso e interessante para os alunos que, a partir da tradução das pequenas histórias, além de aprenderem léxico novo, souberam sobre a vida e os hábitos daquelas personagens, pois traduzir é um viajar em culturas diferentes. E é este o motivo pelo qual a tradução de um texto é uma operação complexa, não tanto pela transposição sintática ou linguística de uma língua para outra, quanto pela transposição

\footnotetext{
"para se ligar às lembranças de nossas vidas, ao mundo da infância, cheio de personagens longínquas, quase indistinguíveis, e sombras do passado, destinados com o tempo a desaparecer totalmente se não fossem, subitamente, fixados no papel para começar a existir de forma autônoma".
} 
cultural que esta comporta, porque se colocam duas culturas lado a lado, cada uma com referências culturais, imaginário e espírito próprios.

Um dos maiores desafios foi a tradução de palavras ou de pequenas frases em dialeto siciliano, que se tornou possível pelas notas explicativas do autor e pelos conhecimentos lexicais da autora deste artigo, que, ainda criança, passava sua férias na Sicília.

Como exemplo, apresentamos algumas frases ditas em dialeto siciliano que tivemos que traduzir antes para o italiano a fim de que os alunos pudessem entender o significado daquelas palavras completamente desconhecidas, e a partir disso pudemos traduzir para o português:

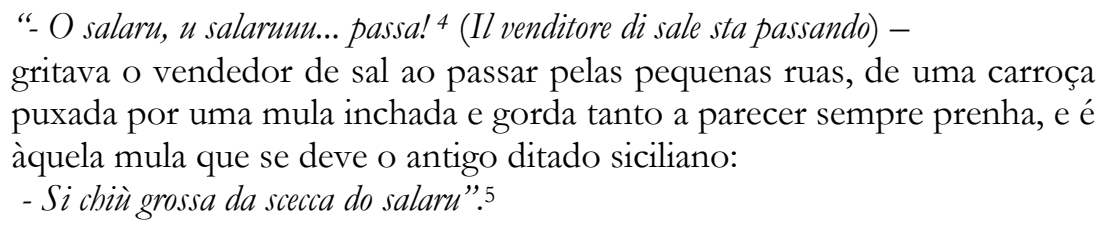
puxada por uma mula inchada e gorda tanto a parecer sempre prenha, e é àquela mula que se deve o antigo ditado siciliano:

- Si chiù grossa da scecca do salaru”. 5

O conto Tio Rocco foi um dos mais difíceis a ser 'lido'. Foi preciso colocar notas para explicarmos termos que não existem, ou que não existem culturalmente, na língua portuguesa: para traduzirmos pale di fichi d'India tivemos que usar, por aproximação, a palavra "folhas" (de figos-da-Índia) porque a palavra italiana "pale" traduz a portuguesa "pás", com a qual, porém, não podemos chamar as "folhas" de figos-da-Índia. Mesmo assim, a explicação ficou difícil pelo fator, que pensamos em chamar, de geográficobotânico: a Sicília, pelo seu clima e pelo seu solo, é grande produtora (e exportadora) do fico d'India (figo da Índia), um tipo de fruta difícil de se achar no Brasil e, portanto, desconhecida da maioria dos brasileiros que não sabe que aquela 'bolota' cheia de espinhos é comestível e é muito gostosa.

\footnotetext{
${ }^{4}$ CHISARI, Mimmo. - O salaru, u salarunu... passa! O vendedor de sal, o vendedor de sal está passando!

5 - Si chiú grossa da scecca do salaru! Você é mais gorda que a mula do vendedor de sal.
} 

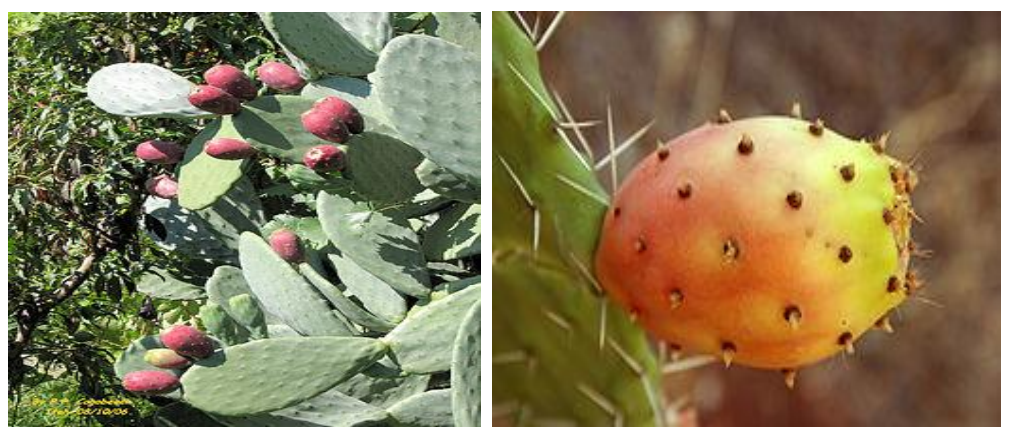

Tudo isso foi bastante proveitoso para os alunos, e deu motivo para lhes dizermos que na tradução, entendida como comunicação escrita, é preciso considerar diversos fatores, a partir dos quais é possível delinear uma distância diacrônica e diatópica, ou ainda geográfica e cultural entre um texto e outro, a cultura para a qual este novo texto se projeta e outros aspectos que cada texto em si possa apresentar.

No conto Lo speziale, que em italiano é o nome que se dava ao odierno farmacêutico, poderíamos ter traduzido, por aproximação, com esta palavra, porém este não prepara, com determinadas dosagens, os medicamentos para os doentes. Então preferimos usar a palavra "Boticário", para não colocarmos mais uma nota explicativa, recurso pouco recomendado, pois as editoras preferem uma leitura que se desenvolva sem que o leitor precise interrompê-la para ler as notas. Fizemos, então, observar aos alunos que quando nos faltam as palavras certas para dizer o que tencionamos, procuramos outras palavras para expressá-las, diferentes daquelas do texto de partida. Mas que deem o mesmo sentido, isto é, que digam... quasi la stessa cosa (como diria Umberto Eco!).

Outro grande desafio foi escolher, entre as traduções individuais, aquela (ou aquelas partes) que mais correspondesse às originais, e quando não encontrávamos uma correspondência perfeita escolhíamos aquela(s) que mais se aproximava(m) ao texto original. Por outro lado, como diz Bruno Osimo, 
isto não acontece somente com os aprendizes, mas também com quem já traduz há certo tempo ${ }^{6}$ :

Toda e qualquer versão, dependendo da forma como o tradutor decide por si próprio que não é possível transpor diretamente na língua ou cultura de chegada, do "resíduo intraduzível", coloca em evidência alguns aspectos e, infelizmente, silencia outros. Em outras palavras, toda a versão difere das outra pelo conteúdo (denotativo, mas principalmente conotativo e estilístico) que o tradutor decidiu sacrificar em nome da comunicabilidade, da "transportabilidade" do texto em questão. (OSIMO, 1998 : 23).

Acompanhando a leitura do livro de Osimo, que usamos, como já foi dito, pela parte teórica e explicativa de nossas aulas, encontramos que ${ }^{7}$ :

[...] se examinarmos uma série de traduções de uma mesma obra, na mesma língua e no mesmo arco histórico, é possível reconstruirmos o mesmo desenvolvimento cultural daquele período, e procurarmos intuir as idiossincrasias dos síngulos tradutores, os tabus sociais, as influências histórico-culturais, as modas lexicais. (OSIMO, 1998:24)

Isso foi verificado no conto Il cantastorie, no qual a personagem conta histórias e canta um pequeno trecho da ópera Cavalleria Rusticana, usando um dialeto um pouco mais antigo daquele de então: - Turiddu, dunque, prima di partire... abbrazzau la matri, prisa di duluri... mentri l'infami, 'nto cori, Iu tradivaaa! (Chisari, 1996:23)

Aqui também tivemos que traduzir antes para o italiano atual: - Então, antes de partir, Salvatore (o nome em forma dialetal do diminutivo Turiddu, o protagonista principal da "Cavalleria Rusticana") abraçara a mãe, tomada pela dor (pois já pressentia que perderia o filho) enquanto o infame lhe traía coração ${ }^{8}$.

\footnotetext{
${ }^{6}$ Ogni versione, a seconda del modo in cui il traduttore decide di farsi carico di cio che non è possibile trasporre direttamente nella língua o cultura di arrivo, del "residuo intraducibile", mette in risalto alcuni aspetti e ne tace, ahimé, altri. In altre parole, ogni versione differisce dalle altre soprattutto per il contenuto (denotativo, ma soprattutto connotativo e stilistico) che il traduttore ha deciso di sacrificare in nome della comunicabilità, della "trasportabilità" del testo in questione. (OSIMO, $1998: 23)$.

${ }^{7}[. .$.$] se si prendono in esame una serie di traduzioni di una stessa opera in una stessa língua in un$ certo arco storico, è possibile ricostruire lo sviluppo culturale di quel periodo, e cercare di intuire le idiosincrasie dei singoli traduttori, i tabú sociali, le influenze storico-culturali, le mode lessicali. (OSIMO, 1998:24)

8 - Allora, prima di partire, Salvatore (il nome in forma dialettale del diminutivo Turiddu, il protagonista principale della "Cavalleria Rusticana") abbracciò la madre, presa dal dolore (poiché già presentiva che avrebbe perso il figlio) mentre l’infame le tradiva il cuore.
} 
A tradução destes contos foi bastante interessante, além de gostosa de fazer, devido às características dos personagens e porque ofereceu palavras novas para os nossos alunos, que agora já são de uso comum na Sicília, por exemplo: Coppola, um tipo de chapéu típico da Sicília; caciotte fresche, que traduzimos com queijo Minas, além de expressões como non restavano nemmeno gli occhi per piangere, traduzida com não tinham nem mesmo os olhos para chorar.

Quando terminamos a tradução, visto que os alunos tinham se apaixonado pelo tipo de trabalho desenvolvido, seguimos a sugestão do autor de Ritratti d'autore, quando na Introdução de seu pequeno livro diz que?:

Todos poderão descrever tipos e lugares particulares de outros países. Cada um poderá acrescentar outros tipos, completando assim, em uma série ideal, os personagens que aqui em seguida apresentaremos: o vendedor de sal, a curadeira, etc..

Será divertido, depois, colocá-los em confronto para descobrir analogias e diferenças. Muitos dos personagens tenderão, de fato, a semelhar-se, no evidente exagero dos defeitos ou na finura dos traços, assumindo características quase universais, como por outro lado tende a semelhar-se todo o gênero humano. (CHISARI, 1996: 3)

Pedimos, então, aos nossos alunos que escrevessem histórias de personagens que até alguns anos atrás povoavam as ruas da periferia do Rio de Janeiro. Disso saíram escritos muito interessantes que ajudarão, sem nenhuma dúvida, o leitor italiano a conhecer a realidade daquela que era a vida dos personagens descritos: pequenos artesãos semelhantes aos contidos em Ritratti d'autore, ou completamente diferentes, afinal a realidade brasileira é diferente da italiana: a baiana, a macumbeira, o vendedor de churrasquinho, o vendedor de cuscuz, o catador de latinhas de cervejas ou de outras bebidas, a faxineira, o amolador de faças...

Eis alguns exemplos:

\footnotetext{
9 Ognuno potrà descrivere tipi e luoghi particolari di altri paesi. Ognuno potrà aggiungere altre figure completando così, in una serie ideale, i personaggi qui di seguito presentati: il venditore di sale, la guaritrice ecc..

Sarà divertente, dopo metterli a confronto per scoprire analogie e differenze. Molti dei personaggi tenderanno, infatti, a rassomigliarsi, nell'evidente esagerazione dei difetti o nella finezza dei tratti, assumendo delle caratteristiche quasi universali, come d'altra parte tende a rassomigliarsi tutto il genere umano. (CHISARI, 1996: 3)
} 


\section{Origem da baiana}

A negra baiana ou simplesmente baiana, como é popularmente conhecida, é a figura mais característica da cidade de Salvador e uma das mais significativas do Brasil.

O traço mais característico é, sem dúvida, a indumentária - composta principalmente pelo turbante muçulmano, compridas e largas saias, vistosos xales e mantas listradas, que lembram os trajes marroquinos - de indiscutível origem islâmica.

Sempre cheia de graça e sorrisos, a baiana está presente nos quatro cantos da terra de Todos os Santos e nos quatro cantos do mundo. Livre, independente, alegre e jovial, recepciona os visitantes, distribui as coloridas e tradicionais fitinhas do Senhor do Bonfim e participa de feiras e grandes eventos.

Sempre irradiando uma particular beleza, não há quem não se renda aos seus encantos e não se prostre diante da sua grandeza, que carrega há centenas de anos e aprimora todos os dias. Por isso, essas mulheres são ícones. Elas fazem, todos os dias a história da Bahia.

\section{Il venditore di spiedini di carne}

Tutte le notti, dopo che le persone cominciavano ad uscire del lavoro, lui era già li: montava la sua "churrasqueira" e un profumo meraviglioso cominciava a spargersi intorno. Le persone lo conoscevano e gli piaceva troppo.

Erano vent'anni che quell'uomo lavorava lì, e se qualche giorno non ci fosse, i suoi avventori se ne preoccupavano. Il sabato il suo orario era differente: il venditore cominciava la mattina. E non era da sorprendere: le persone aspettavano quello che era, durante la settimana, la loro cena, ed il sabato, il loro pranzo.

Quest'uomo è un personaggio reale, si chiama Wilson, ed è il mio babbo.

No livro corpus desse trabalho alguns personagens se assemelham a pessoas brasileiras, como La guaritrice, que seria a nossa Rezadeira e não a Macumbeira, como diz o próprio autor em sua nota explicativa ${ }^{10}$ :

[...] diferentemente da feiteceira que, esperta em feitiços, faz, com intentos maléficos, obras de bruxaria, encantesimos, etc., a curandeira ajuda, com rituais e exorcismos benéficos, aqueles que se encontram em estado de mal-estar. (CHISARI, 1996:6)

Há também outras personagens comuns aos brasileiros, que encontramos pelas ruas da cidadezinha, como Il fotografo, célebre aqui também

${ }^{10}$ [...] a differenza della maga (magara) che, esperta di stregoneria, compie, con intenti malefici, delle opere di affatturamento, la guaritrice aiuta, con riti ed esorcismi benefici, coloro che si trovano in uno stato di malessere. (CHISARI, 1996:6) 
há até alguns anos, quando nem na Sicília nem no Rio de Janeiro existiam as atuais e rápidas máquinas fotográficas ${ }^{11}$.

Há algum tempo, quando Yashica parecia o nome de uma princesa oriental e a palavra zoom não existia, ainda, em nosso vocabulário, caminhava, pelas ruas da pequena cidade, um senhor com bigodinhos pretos e óculos escuros que assim se anunciava: - Fotógrafo... Fotografias...! [...] Depois de algumas semanas a fotografia era bem pronta para ser colocada na moldura apropriada. (CHISARI, 1996)

E havia aqui e ali, assim como ainda há, o portalettere, que muitos chamavam de postino, e que equivale ao nosso carteiro. A diferença é que o carteiro aqui descrito possui algumas particularidades... ${ }^{12}$

Para entregar com cuidado as cartas, o carteiro recebia, em pagamento, produtos naturais: queijos frescos, frangos caipiras, frutas e verduras, massas e muitas garrafas de vinho. [...] O carteiro comia e bebia, excessivamente, à custa de todos, embriagando-se, muitas vezes, de modo exagerado.

Um dia, porém, foi encontrado morto [...] Espalhadas dentro do forno, foram encontradas centenas de cartas escritas por jovens soldados que, há tempo, tinham sido dados como mortos.

Para concluirmos, gostaríamos de dizer que para a tradução dos contos do livrinho, os tradutores, no nosso caso os alunos, tinham à disposição somente o recurso de anotações explicativas no texto, como notas de rodapé. Para alguns teóricos isso equivaleria a uma 'derrota' da tradução, e então, do tradutor. Para nós, porém, esta é uma consequência inelutável da incomensurabilidade de dois sistemas linguísticos, e, portanto, inevitável. De fato, se pressupormos que as línguas naturais usam segmentações diferentes,

\footnotetext{
${ }^{11}$ Tempo fa, quando Yashica sembrava il nome di una principessa orientale e la parola room non esisteva, ancora, nel nostro vocabolario, camminava, per le vie del paese, un signore con baffetti neri ed occhiali scuri così annunciandosi: - Fotografo... fotografie...! [...] Dopo alcune settimane la fotografia era bella e pronta per essere inserita nell'apposita cornice. (CHISARI, 1996:12)
}

12 Per consegnare con sollecitudine, le lettere il postino si faceva pagare in natura: caciotte fresce, galletti ruspanti, frutta e verdura, pasta e tanti fiaschi di vino. [...] Il portalettere mangiava e beveva, smoderatamente, alla faccia di tutti, ubriacandosi, spesso, in modo eccessivo. Un giorno, però, fu trovato morto [...] Sparse dentro il forno, furono rinvenute centinaia di lettere, scritte da giovani soldati che, già da tempo venivano pianti come morti.. (CHISARI, 1996: 44) 
descrevendo a 'realidade' ou mundos possíveis, uma tradução palavra por palavra não é possível, mas é se, ao invés disso, for uma tradução explicativa.

\section{Referências bibliográficas}

CAMPOS. Haroldo de. Paul Valery e a poética da tradução. In Limites da traduribilidade. Salvador: EDUFBA, 1966.

CHISARI, Mimmo. Ritratti d'autore - personaggi e tradizioni del passato. Personal Editor, 1996.

LAGES, Susana K. \& BENJAMIN, Walter. Tradução e melancolia. São Paulo: EDUSP, 2002.

LARANJEIRA, Mário. Poética da tradução: do sentido à significância. EDUSP FAPESP.

MARTINS, Claudia de Rezende \& CORREA, Angela. Estratégias do processo tradutório. In Estudos de tradutologia. Vol. 1, Brasília: Kontakt, 1981.

FONTES, Martins. Dicionário Martins Fontes - Italiano/Português. São Paulo: Martins Fontes, 2004.

OSIMO, Bruno. Manuale del traduttore - Guida pratico e Glossário. Milano: Editore Ulrico Hoelpi, 1998.

OTTONI, Paulo (org). Tradução: a prática da diferença. Campinas, SP: Editora da UNICAMP, FAPESP, 1998.

PAES, José Paulo. Traducão, a ponte necessária. Aspectos e problemas da arte de traduzir. São Paulo: Ática, 1990. 
NERGRAARD, Siri (a cura di). Teorie contemporanee della traduzione. Testi di Jakobson, Levý, Lotman, Toury, Eco, Mida, Zohaar, Holmes, Meschonnic, Paz, Quine, Gadamer, Derrida. Milano: I Edizione Strumenti Bompiani, 1995.

FROTA, Maria Paula. Tradução, Pós-Estruturalismo e Interpretação. In Cadernos de tradução. $\mathrm{n}^{\circ}$ 1. G.T. de Tradução da Universidade Federal de Santa Catarina, Florianópolis, 1996.

SILVESTRO, Elio (Direttore Responsabile). La traduzione - Saggi e documenti (II) - Libri e riviste d'Italia. Ministero per i beni culturali e ambientali, Stampato dall'Istituto Poligrafico e Zecca dello Stato, 1995. 